Revta brasil. Bot., São Paulo, V.24, n.1, p.85-97, mar. 2001

\title{
Morfologia comparada de plântulas e plantas jovens de leguminosas arbóreas nativas: espécies de Phaseoleae, Sophoreae, Swartzieae e Tephrosieae ${ }^{1}$
}

\author{
DENISE MARIA TROMBERT OLIVEIRA ${ }^{2,3}$
}

(recebido: 10 de maio de 2000; aceito: 8 de novembro de 2000)

\begin{abstract}
Comparative morphology of seedlings and saplings of species of the native leguminous trees: species of Phaseoleae, Sophoreae, Swartzieae and Tephrosieae). In this paper, seedlings and saplings of Erythrina speciosa (Phaseoleae), Holocalyx balansae and Sophora tomentosa (Sophoreae), Swartzia langsdorffii (Swartzieae), Lonchocarpus muehlbergianus and Platycyamus regnellii (Tephrosieae) were studied, aiming to describe the morphology at early developmental stages of leguminous trees, in order to identify species, and provide information for taxonomic, phylogenetic and ecological works. Erythrina speciosa showed epigeal-fleshy seedlings with two eophylls only. The species of Sophoreae and Swartzieae formed hypogeal seedlings with 5-7 eophylls in Holocalyx balansae, 6-15 in Sophora tomentosa and 7-10 in Swartzia langsdorffii. In Tephrosieae, Lonchocarpus muehlbergianus showed hypogeal seedlings with 8-10 eophylls, while Platycyamus regnellii had epigeal-fleshy seedlings with two eophylls only. Seedlings and saplings of Erythrina speciosa and Platycyamus regnellii are similar and are distinguished only by the presence of spines and extra-floral nectaries in the former. The phyllotaxy of Sophoreae and Swartzieae show alternate nodes, while in Phaseoleae and Tephrosieae the first node is opposite, becoming alternate in the subsequent ones. Radicular nodules were observed in all species but Holocalyx balansae and Platycyamus regnellii.
\end{abstract}

RESUMO - (Morfologia comparada de plântulas e plantas jovens de leguminosas arbóreas nativas: espécies de Phaseoleae, Sophoreae, Swartzieae e Tephrosieae). Dados morfológicos referentes às fases juvenis das plantas são tão importantes quanto escassos na literatura. Neste trabalho, foram estudadas as plântulas e plantas jovens de Erythrina speciosa (Phaseoleae), Holocalyx balansae e Sophora tomentosa (Sophoreae), Swartzia langsdorffii (Swartzieae), Lonchocarpus muehlbergianus e Platycyamus regnellii (Tephrosieae), como parte de um amplo projeto com leguminosas arbóreas, que objetivou descrever a morfologia das fases juvenis, com vistas à identificação das espécies, fornecendo subsídios para trabalhos taxonômicos, filogenéticos e ecológicos. Erythrina speciosa apresentou plântula epígeo-carnosa, formando somente dois eofilos. As espécies de Sophoreae e Swartzieae formaram plântulas hipógeas, sendo constituídos de cinco a sete eofilos em Holocalyx balansae, de seis a $15 \mathrm{em}$ Sophora tomentosa e de sete a $10 \mathrm{em}$ Swartzia langsdorffii. Em Tephrosieae, Lonchocarpus muehlbergianus produziu plântula hipógea e constituiu de oito a 10 eofilos e Platycyamus regnellii formou plântulas epígeo-carnosas e apenas dois eofilos. As plântulas e plantas jovens de Erythrina speciosa e de Platycyamus regnellii são similares, sendo distinguidas somente pela presença de espinhos e nectários extra-florais na primeira. Com relação à filotaxia, as espécies de Sophoreae e Swartzieae apresentaram somente nós alternos, enquanto que, em Phaseoleae e Tephrosieae, a filotaxia do primeiro nó eofilar foi oposta, passando a alterna nos nós subsequentes. Foram encontrados nódulos radiculares em todas as espécies, exceto em Holocalyx balansae e em Platycyamus regnellii.

Key words - Seedling, sapling, morphology, Fabaceae, Faboideae

\section{Introdução}

A família Fabaceae compreende aproximadamente 650 gêneros e 18.000 espécies, distribuídas nas subfamílias Caesalpinioideae, Faboideae e Mimosoideae (Polhill et al. 1981). A maior delas é Faboideae, que inclui cerca de 440 gêneros e 12.000 espécies, estando bem representada nas regiões tropicais. Nesta subfamília, várias tribos incluem espécies arbóreas, dentre elas Swartzieae, que é essencialmente sul-americana, e Phaseoleae,

1. Parte da tese de doutorado da autora.

2. Universidade Estadual Paulista, UNESP, Instituto de Biociências, Departamento de Botânica, Caixa Postal 510, Rubião Júnior, 18618-000 Botucatu, SP, Brasil.

3. Autor para correspondência: doliveira@laser.com.br
Sophoreae e Tephrosieae, que têm distribuição pantropical (Polhill 1981).

Considerando-se o grande número de espécies de leguminosas, fica evidente a existência de problemas taxonômicos e impasses filogenéticos, que a análise tradicional de órgãos vegetativos e florais é insuficiente para solucionar. Desta forma, é necessário o estudo de frutos, sementes, plântulas e plantas jovens, não somente com propósitos taxonômicos, filogenéticos ou ecológicos, mas também como contribuições ao conhecimento destas espécies.

É importante lembrar que a combinação de características da semente e do indivíduo adulto, representada pela plântula, pode fornecer numerosos indícios para a identificação das espécies no campo ou em amostras de sementes (Ng 1978, Amo 1979, Duke \& Polhill 1981, Parra 1984). O maior problema 
é que, além de ser um período crítico do ciclo de vida de muitas espécies, a fase de plântula é também pouco conhecida. A necessidade de trabalhos visando ao esclarecimento da estrutura das plântulas vem sendo ressaltada desde o início do século (Compton 1912); atualmente, porém, os dados disponíveis ainda são escassos, conforme salienta Garwood (1995).

A capacidade de se reconhecerem, num dado momento, as plântulas e plantas jovens na mata pode ser de grande valor para se estabelecer a dinâmica de populações da mesma e o manejo silvicultural de muitas matas semelhantes (Silva et al. 1988). Pode também servir como índice para se reconhecer o estágio sucessional de uma vegetação, segundo a diversidade de espécies e indivíduos que dominam o solo (Amo 1979, Torres 1985). A compilação de resultados sobre a velocidade de germinação de sementes, aliada aos dados de morfologia e desenvolvimento de plântulas, são muito úteis nos trabalhos em viveiros e em pesquisas sobre armazenamento de sementes e regeneração de florestas $(\mathrm{Ng}$ 1973).

A ação humana tem levado muitos ambientes naturais a alterações que os desfiguram irreversivelmente. Esta situação torna-se ainda mais grave devido ao desconhecimento das estratégias de regeneração espontânea, do crescimento de espécies primárias ou secundárias, do abortamento de sementes e da mortalidade de plântulas, das taxas de crescimento das espécies nativas e de sua fenologia (Torres 1985). Especialmente nas regiões neotropicais, o desmatamento indiscriminado tem provocado a extinção de diversas espécies vegetais, colocando em risco numerosas outras. No ponto de vista de Garwood \& Humphries (1993), para reverter essa desastrosa tendência de desmatamento e extinção em regiões tropicais, é necessária habilidade para manejar e conservar os remanescentes florestais, constituindo áreas de proteção ambiental ou de manejo sustentável, restaurando-se, também, as áreas já devastadas. No entanto, o manejo, a conservação e a reconstituição de florestas tropicais dependem da compreensão da ecologia tropical que, por sua vez, está atrelada à realização de estudos que permitam a precisa identificação das espécies vegetais a partir de suas fases juvenis.

Além desses aspectos, o estudo da morfologia das plântulas em sua primeira fase de desenvol- vimento, antes da produção das folhas definitivas, permite a descoberta de estruturas transitórias, primitivas ou derivadas, as quais desaparecem com o desenvolvimento da planta, mas que podem ter extraordinária importância para se estabelecer conexões filogenéticas com os grupos em que os órgãos adultos apresentem tais características (Ricardi et al. 1977, Torres 1985).

Com base nesses pressupostos, realizou-se um amplo estudo morfológico comparativo de espécies arbóreas de leguminosas, enfocando a estrutura de seus frutos, sementes, plântulas e plantas jovens. Neste trabalho, são apresentados os dados referentes às plântulas e plantas jovens de espécies de Phaseoleae, Sophoreae, Swartzieae e Tephrosieae (Faboideae), objetivando fornecer informações sobre o tipo de germinação das sementes, bem como descrever a morfologia das plântulas e plantas jovens, como subsídios para trabalhos taxonômicos, filogenéticos e ecológicos da família.

\section{Material e métodos}

Sementes maduras de espécies das tribos em estudo foram coletadas em remanescentes de mata e nos câmpus da Universidade Estadual Paulista em Botucatu, São Paulo, com exceção de Sophora tomentosa, que foi coletada em Picinguaba, São Paulo. Foram preparadas exsicatas dos indivíduos utilizados para coleta, sendo o material incorporado ao Herbarium Rioclarense (HRCB), pertencente ao Departamento de Botânica, Instituto de Biociências, UNESP - Rio Claro, como documento taxonômico. Foram estudadas as seguintes espécies:

Tribo Phaseoleae: Erythrina speciosa Andrews: eritrinacandelabro, mulungu-do-litoral - HRCB 26511;

Tribo Sophoreae: Holocalyx balansae Mich.: alecrim-decampinas - HRCB 26497 (sinonímia: Holocalyx glaziovii Taub.) e Sophora tomentosa L.: sofora - HRCB 17928;

Tribo Swartzieae: Swartzia langsdorffii Raddi: pacová-demacaco, jacarandá-banana - HRCB 26505;

Tribo Tephrosieae: Lonchocarpus muehlbergianus Hassl.: embira-de-sapo - HRCB 26496 e Platycyamus regnellii Benth.: pau-pereira - HRCB 26499.

Para os estudos do desenvolvimento pós-seminal, as amostras de sementes duras foram desinfectadas em hipoclorito de sódio a $20 \%$ da solução comercial por $15 \mathrm{~min}$, sendo lavadas em água corrente até se desprender o cheiro; sementes com tegumento delgado permaneceram na solução por somente cinco minutos, seguindo-se a lavagem. Antes de se proceder à desinfecção, eliminaram-se os arilos das sementes de Swartzia langsdorffii. Cada semente dura foi escarificada mecanicamente, utilizando-se uma lima.

Uma amostra de 50 sementes foi colocada para germinar em germinador modelo NT708, em caixas tipo gerbox, entre folhas de papel de filtro umedecidas com água destilada, sendo mantidas 
a $25 \pm 1{ }^{\circ} \mathrm{C}$, sob iluminação fluorescente branca contínua (lâmpadas Phillips, tipo luz do dia). Antes das plântulas atingirem o tamanho da caixa, foram transplantadas para sacos de polietileno próprios para produção de mudas, contendo mistura de terra e areia em partes iguais, sendo mantidas em casa-de-vegetação, sob sombrite $50 \%$ e regadas diariamente. Foram realizadas observações diárias, anotando-se a data de semeadura, do início da germinação (determinado pela emergência da raiz primária) e o desenvolvimento das plântulas e plantas jovens, até a formação do primeiro metafilo. Foram descritos o tipo de morfologia inicial da plântula, o desenvolvimento da raiz, hipocótilo e epicótilo, a ocorrência de nódulos radiculares, o tipo e a morfologia dos cotilédones, dos eofilos e dos metafilos.

Paralelamente, semeou-se outra amostra de 50 sementes de cada espécie em bandejas plásticas, contendo mistura de terra e areia em partes iguais, sendo mantidas em casa-de-vegetação sob condições ambientais, cobertas por sombrite 50\% e regadas diariamente. As plântulas obtidas foram transplantadas para sacos de polietileno com substrato semelhante, sendo mantidas e acompanhadas na estufa de sombrite. As observações realizadas nestes indivíduos complementaram as realizadas naqueles obtidos em germinador. Foram consideradas germinadas as sementes que apresentaram hipocótilo ou epicótilo emergindo do solo, conforme o padrão da espécie.

Das plântulas e plantas jovens obtidas, alguns exemplares foram conservados em etanol a 70\% e outros foram prensados. Para as descrições e ilustrações, foram utilizados preferencialmente espécimes vivos, complementando-se as informações com indivíduos secos ou conservados em álcool.

A terminologia empregada na descrição das plântulas baseou-se nos trabalhos de Duke (1965, 1969), Duke \& Polhill (1981), Garwood (1983, 1995), Parra (1984) e em Miquel (1987). Considerou-se plântula a fase transcorrida entre a emissão da raiz primária e a expansão do primeiro eofilo (ou primeiro par) e planta jovem as diversas formas apresentadas pelo indivíduo até a produção e expansão do primeiro metafilo (sensu Oliveira 1997). A definição do metafilo das espécies estudadas foi feita com base na análise das plantas utilizadas como matrizes, bem como em informações da literatura (Burkart 1952, Lorenzi 1992).

As escalas de todas as ilustrações foram obtidas de modo usual, nas condições ópticas adequadas a cada caso. Os desenhos das fases iniciais do desenvolvimento das plântulas foram feitos em câmara clara adaptada ao microscópio estereoscópio e os dos indivíduos jovens foram elaborados a olho nu.

\section{Resultados}

1. Tribo Phaseoleae

1.1 Erythrina speciosa Andrews - Em germinador, verificou-se $100 \%$ de germinação e, em estufa de sombrite, 97\%. A morfologia inicial da plântula é epígeo-carnosa. A germinação começa com a protrusão da raiz primária branca e grossa, aos dois dias (figura 1). O crescimento da raiz é rápido (figura 2), podendo-se observar, aos cinco dias, várias raízes laterais e o hipocótilo em crescimento, elevando os cotilédones acima do solo (figura 3 ). Com 10 dias, o epicótilo já se alonga e está delineado o primeiro par de eofilos, opostos cruzados em relação aos cotilédones. Nessa fase, os cotilédones carnosos estão livres do tegumento e tornam-se fotossintéticos.

Aos 16 dias, pode-se descrever a plântula (figura 4), cujo sistema radicular é axial, com várias raízes secundárias e terciárias. $\mathrm{O}$ hipocótilo curto e o epicótilo apresentam coloração verde clara. Os cotilédones continuam verdes, de tonalidade mais escura que o caule. O primeiro par de eofilos apresenta-se unifoliolado, de limbo cordiforme, distinguindo-se o pulvínulo na base foliolar, bem como um par de pequenos nectários globosos; a folha é peciolada e, em sua base, distingue-se um par de estípulas foliáceas caducas. Já nesta fase, inicia-se a diferenciação de espinhos em toda a extensão do caule e no limbo e pecíolo dos eofilos.

O desenvolvimento da planta jovem é rápido, observando-se, a partir do primeiro par de eofilos, a mudança da filotaxia, que passa a ser alterna. A abscisão cotiledonar ocorre aos 25 dias, quando o segundo nó foliar está em diferenciação. Não são produzidos outros eofilos, verificando-se, em torno de 30 dias (figura 5), o primeiro metafilo. Este é trifoliolado, com dois nectários globosos na base do pulvínulo de cada folíolo; é peciolado, havendo duas estípulas foliáceas caducas em sua base. Muitos espinhos podem ser observados tanto nos folíolos quanto no pecíolo, além do caule.

O sistema radicular da planta jovem desenvolve-se bastante, apresentando numerosas ramificações. Nódulos radiculares de formato irregular, mais ou menos alongados, podem ser observados na espessa raiz principal, bem como nas laterais.

\section{Tribo Sophoreae}

2.1. Holocalyx balansae Mich. - A morfologia inicial da plântula é hipógea, obtendo-se $70 \%$ de germinação em germinador e $74 \%$ em estufa de sombrite. $\mathrm{O}$ processo de germinação inicia-se lentamente, cerca de 14 dias após a semeadura, pela protrusão da raiz primária, que se assemelha a um calo (figura 6 ). Seu alongamento ocorre até o 25 dia, quando se evidencia o hipocótilo, muito curto (figura 7). A emissão do epicótilo se dá por volta dos 30 dias, exibindo imediatamente o primeiro catafilo alterno (figura 8). Segue-se a produção de mais quatro a cinco catafilos alternos, após os quais se diferencia o primeiro eofilo, aos 45 dias (figura 9). Este é 


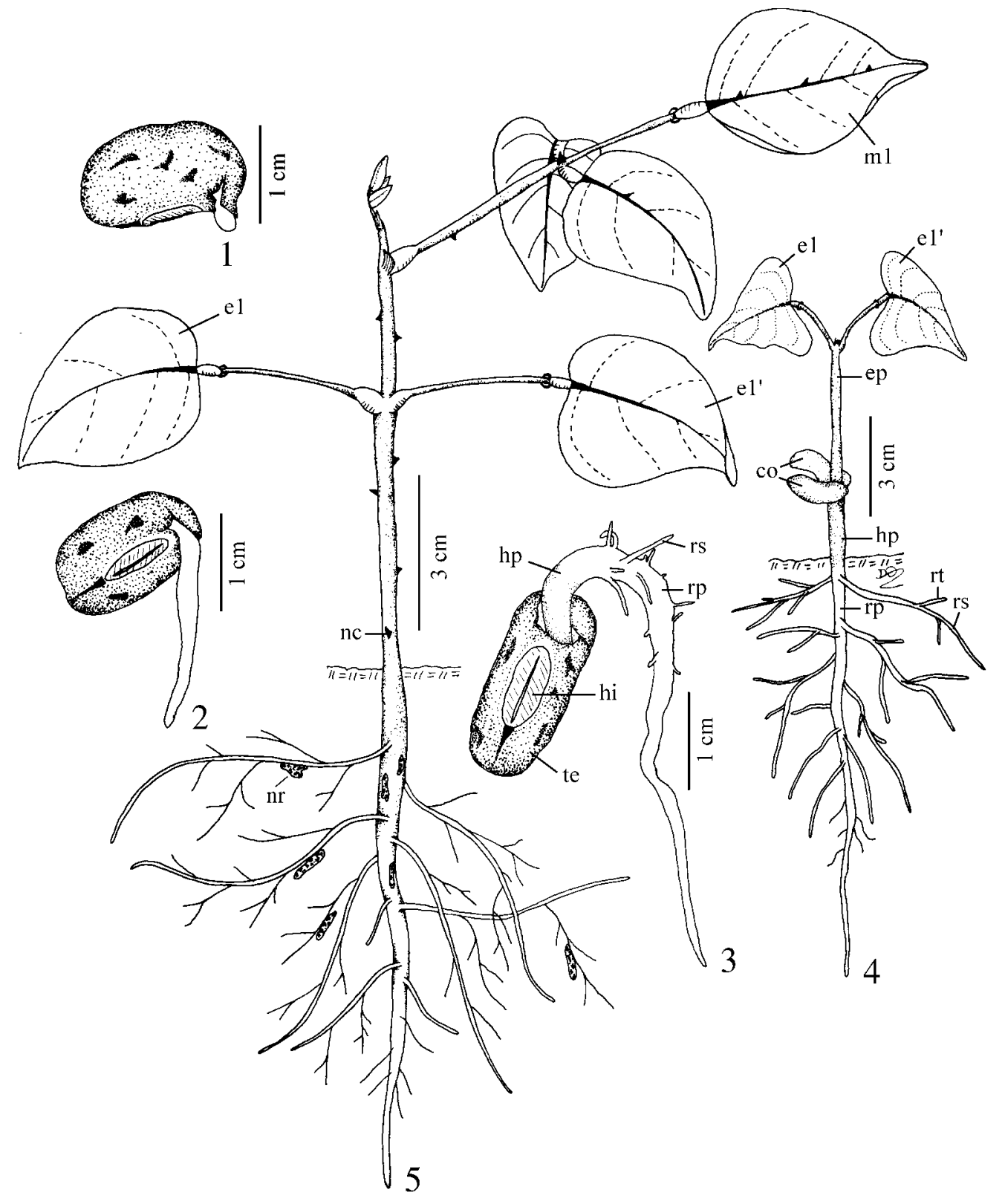

Figuras 1-5. Erythrina speciosa. 1-4. plântula. 1. com 2 dias. 2. com 3 dias. 3. com 5 dias. 4. com 16 dias. 5. planta jovem com 30 dias. (co: cotilédone, e1-e1': primeiro par de eofilos, ep: epicótilo, hi: hilo, hp: hipocótilo, m1: primeiro metafilo, nc: nó cotiledonar, nr: nódulo radicular, rp: raiz primária, rs: raiz secundária, rt: raiz terciária, te: tegumento).

alterno, pinado, bifoliolado, curto-peciolado, pulvinado e com um par de estípulas filiformes curtas em sua base. Um par de estipelas rígidas e curtas pode ser observado na base dos folíolos. O sistema radicu- laré simples, constituído pela raiz pivotante e poucas raízes secundárias de pequeno tamanho.

O segundo eofilo produzido já apresenta 12 folíolos subopostos, sendo, nos demais atributos, 

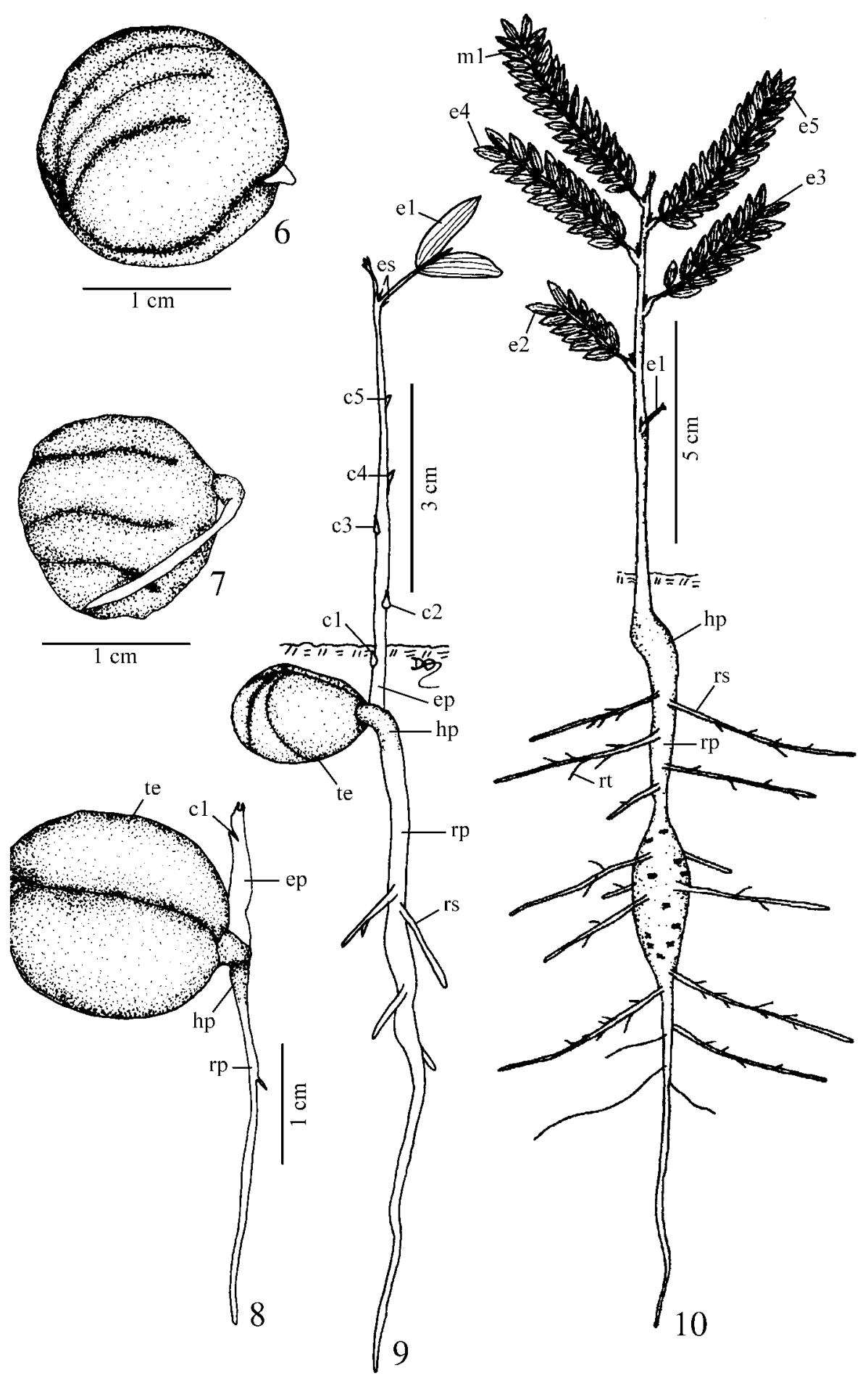

Figuras 6-10. Holocalyx balansae. 6-9. plântula. 6. com 14 dias. 7. com 25 dias. 8. com 32 dias. 9. com 45 dias. 10. planta jovem com 4 meses. (c1-c5: série de catafilos, e1-e5: série de eofilos, ep: epicótilo, es: estípula, hp: hipocótilo, m1: primeiro metafilo, rp: raiz primária, rs: raiz secundária, rt: raiz terciária, te: tegumento). 
semelhante ao primeiro. Sequencialmente, formamse mais três a cinco eofilos, nos quais são acrescentados de dois a três pares de folíolos também subopostos. Quando a planta jovem possui aproximadamente quatro eofilos, em torno dos três meses, ocorre a queda dos cotilédones. Em Holocalyx balansae, todos os entrenós são pouco alongados. $\mathrm{O}$ primeiro metafilo é produzido aos quatro meses (figura 10), sendo pinado e constituído por 15 pares de folíolos, dispostos subopostamente sobre a ráquis. Nas folhas mais velhas, ocorre a queda dos folíolos, mantendo por algum tempo na planta o pecíolo e a ráquis, com os pares de estipelas muito nítidos e rígidos.

O sistema radicular apresenta-se bem ramificado, sem a ocorrência de nódulos. Ocorre tuberização de parte da raiz principal e, algumas vezes, de secundárias; na região tuberizada, numerosas lenticelas arredondadas e grandes podem ser observadas, ao lado de finas ramificações.

2.2. Sophora tomentosa L. - A germinação atingiu níveis indistintos em germinador e em estufa de sombrite, observando-se, respectivamente, $84 \%$ e $86 \%$ de germinação. A morfologia inicial da plântula é hipógea, iniciando-se o processo de germinação aos três dias, pela emissão da raiz primária branca (figura 11). Logo aos cinco dias, diferencia-se o curto hipocótilo, amarronzado (figura 12). Então, a raiz se alonga até os nove dias, quando tem início a diferenciação do epicótilo, que torna-se visível entre as bases dos cotilédones (figura 13). A seguir, formam-se de três a cinco pequenos catafilos alternos (figura 14), sucedidos pelo primeiro eofilo, também alterno, expandido cerca de 30 dias após a semeadura (figura 15). Este apresenta pulvino de cor laranja, ligado pelo pecíolo ao limbo unifoliolado, pulvinulado; o pulvínulo também tem coloração laranja, sendo distinguível à distância. $\mathrm{O}$ sistema radicular da plântula exibe distinta raiz axial e algumas poucas raízes laterais, nas quais já se verificam alguns nódulos radiculares.

Segue-se a produção de mais um ou dois eofilos unifoliolados, a partir do que são seqüencialmente produzidos de um a três eofilos em que se incrementam dois folíolos até um total de 11 unidades, mantendo-se a morfologia geral descrita. Quando a planta jovem apresenta quatro a seis eofilos, ocorre a abscisão dos cotilédones, cerca de quatro meses após a semeadura.

Por volta do oitavo mês (figura 16), é produzido o primeiro metafilo, composto por 13 folíolos, cujos limbos apresentam a face adaxial verde escura brilhante e a abaxial verde clara e fosca, ambas de aspecto glabro; fina pilosidade branca recobre o eixo vegetativo aéreo, que é verde claro. O sistema radicular da planta jovem exibe raiz primária longa e bem espessada, com muitas lenticelas arredondadas e grandes, sendo bastante ramificado. Ocorre grande quantidade de nódulos radiculares alongados e ramificados, exclusivamente nas delgadas raízes laterais.

\section{Tribo Swartzieae}

3.1. Swartzia langsdorffii Raddi - A germinação é lenta e irregular. Das sementes colocadas em germinador, obteve-se $48 \%$ de germinação, contra $36 \%$ daquelas em estufa de sombrite. A morfologia inicial da plântula é hipógea e todo o desenvolvimento pós-seminal é lento. Cerca de 17 dias após a semeadura, observa-se a emergência da raiz primária, muito grossa e de coloração esbranquiçada, entre rachaduras no tegumento, que não se desprende (figura 17). Até o 32- dia, só ocorre alongamento da raiz (figura 18), que se ramifica em torno do 53ㅇdia, quando o epicótilo já se encontra em crescimento (figura 19).

Durante a fase de crescimento do epicótilo, são produzidos, entre os 70 e 85 dias, de três a cinco catafilos alternos (figura 20). A plântula torna-se completa aos quatro meses, com a formação do primeiro eofilo (figura 21), que é alterno e trifoliolado, apresentando pecíolo discretamente alado, pulvino e um par de estípulas filiformes longas em sua base. Os folíolos são sésseis e pulvinulados, têm aspecto glabro e brilhante, especialmente na face adaxial.

Após o primeiro eofilo, a planta jovem apresenta a formação de mais dois ou três eofilos trifoliolados, sendo incrementados dois folíolos a cada dois eofilos produzidos. Deste modo, são lentamente produzidos de quatro a seis eofilos. A abscisão cotiledonar se dá por volta do sexto mês, quando a planta jovem apresenta de três a quatro eofilos formados. Aos 13 meses (figura 22), é produzido o primeiro metafilo, alterno, apresentando a base foliar modificada em pulvino e um par de estípulas filiformes longas e persistentes, com pecíolo e ráquis dis- 


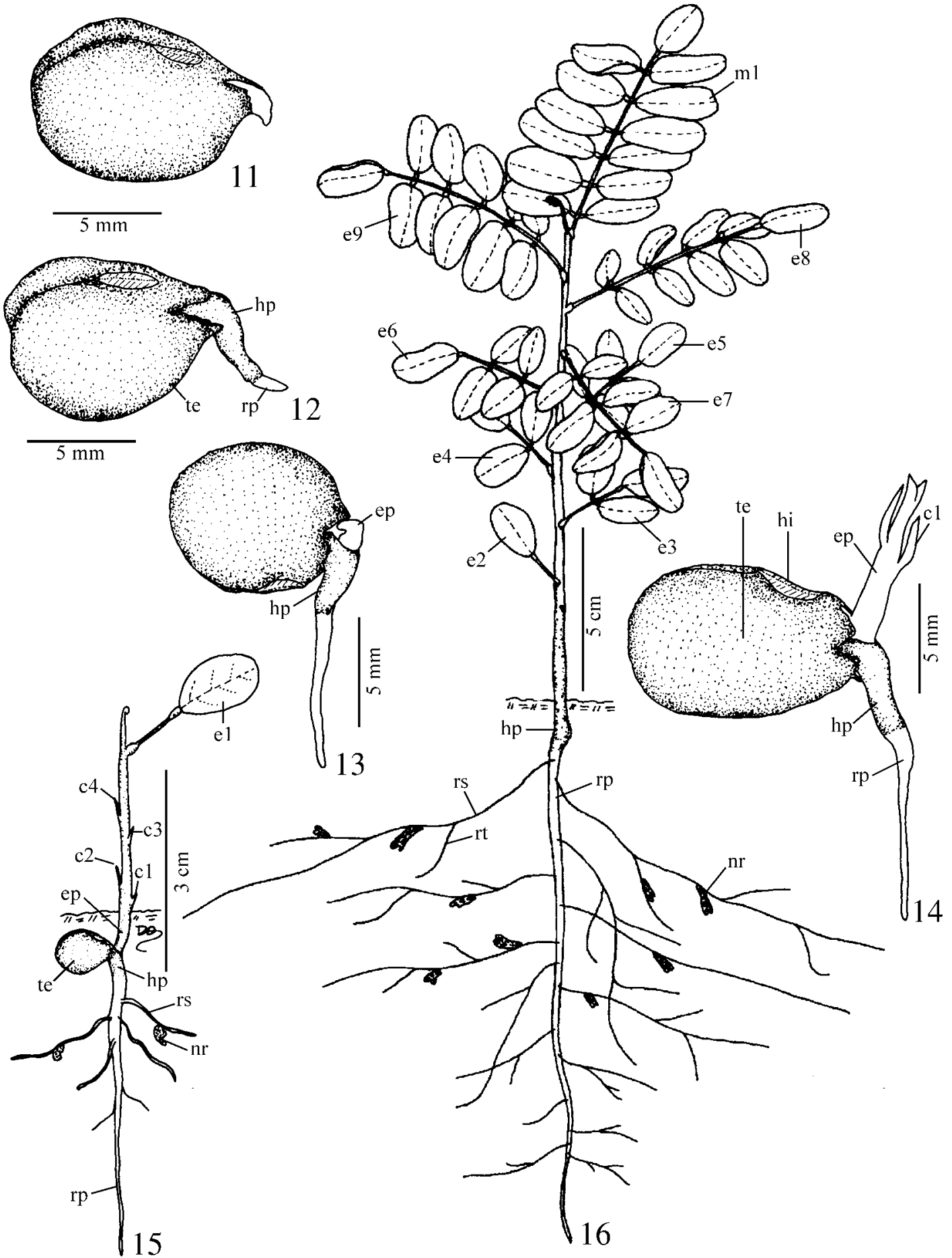

Figuras 11-16. Sophora tomentosa. 11-15. plântula: 11. com 3 dias. 12. com 5 dias. 13. com 9 dias. 14. com 15 dias. 15 . com 30 dias. 16. planta jovem com 8 meses. (c1-c4: série de catafilos, e1-e9: série de eofilos, ep: epicótilo, hi: hilo, hp: hipocótilo, m1: primeiro metafilo, nr: nódulo radicular, rp: raiz primária, rs: raiz secundária, rt: raiz terciária, te: tegumento). 


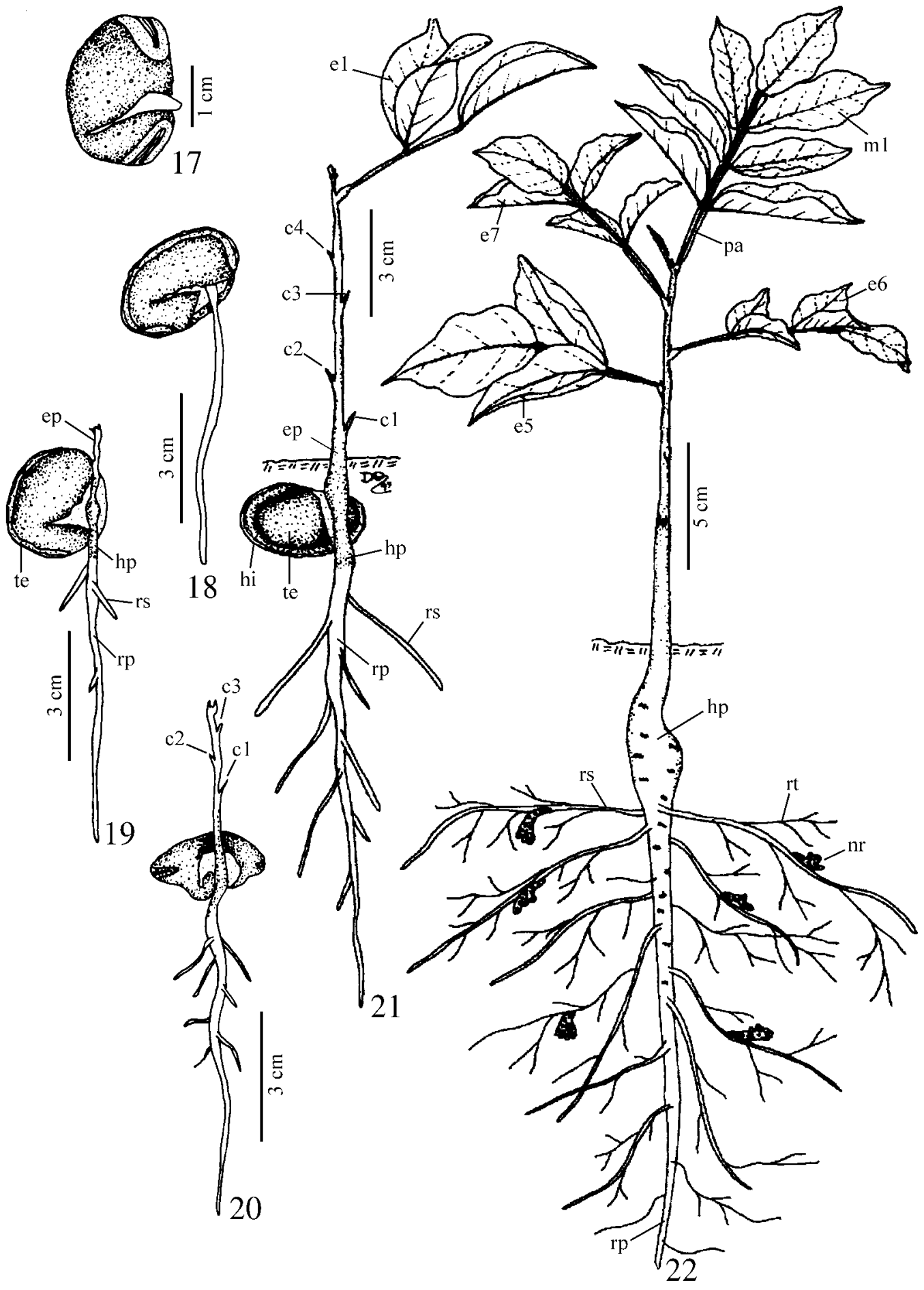

Figuras 17-22. Swartzia langsdorffii. 17-21. plântula. 17. com 17 dias. 18. com 32 dias. 19. com 53 dias. 20. com 80 dias. 21. com 4 meses. 22. planta jovem com 13 meses. (c1-c4: série de catafilos, e1, e5-e7: série de eofilos, ep: epicótilo, hi: hilo, hp: hipocótilo, m1: primeiro metafilo, nr: nódulo radicular, pa: pecíolo alado, rp: raiz primária, rs: raiz secundária, rt: raiz terciária, te: tegumento). 
cretamente alados, composto por sete folíolos sésseis, pulvinulados, de limbo coriáceo, liso e brilhante, com bordos ondulados.

Na planta jovem, o nó cotiledonar apresenta-se bem espessado. A raiz principal, bastante espessa, exibe grandes lenticelas e não apresenta nodulação. As raízes laterais são bem mais delgadas, com longos nódulos bem ramificados.

\section{Tribo Tephrosieae}

4.1. Lonchocarpus muehlbergianus Hassl. - A morfologia inicial da plântula é hipógea, obtendo-se $76 \%$ de sementes germinadas em germinador e $44 \%$ em estufa de sombrite. $\mathrm{O}$ processo germinativo torna-se visível aos três dias, com a emissão da raiz primária branca (figura 23), que se alonga até o oitavo dia (figura 24). Aos nove dias, inicia-se a emissão do epicótilo, que surge entre os dois cotilédones, os quais permanecem retidos no tegumento. Com 12 dias, o epicótilo está bastante alongado, delineia-se o primeiro par de eofilos e surgem as primeiras ramificações radiculares (figura 25). Por volta do $20^{\circ}$ dia, os dois primeiros eofilos podem ser descritos (figura 26), sendo opostos, peciolados e com pulvino, unifoliolados, com o grande folíolo cordiforme, séssil e pulvinulado, de intensa coloração verdemusgo.

A partir do segundo nó eofilar, a filotaxia tornase alterna. Seguem-se dois a três eofilos com características morfológicas semelhantes às dos primeiros, sendo porém trifoliolados. A queda dos cotilédones ocorre nesta fase, cerca de dois meses após a semeadura. Formam-se novos eofilos (de quatro a seis unidades), nos quais o número de folíolos aumenta, passando de três para sete.

O metafilo é produzido aos seis meses (figura 27), apresentando pulvino grande, longo pecíolo e limbo pinado, com nove folíolos, sendo os distais de maior tamanho. Os folíolos são longo-pulvinulados, ocorrendo inclusive encurvamento dos pulvínulos, especialmente junto ao folíolo apical.

O caule é verde-acinzentado, delgado no ápice, ocorrendo numerosas lenticelas de pequeno tamanho em toda a sua extensão. O sistema radicular conta com raiz principal espessa, onde se observam lenticelas como as do caule; raízes secundárias e terciárias são bem mais finas que a principal, apresentando nódulos pouco longos, ramificados.
4.2. Platycyamus regnellii Benth. - A morfologia inicial da plântula é epígeo-carnosa, obtendo-se $16 \%$ de sementes germinadas tanto em germinador quanto em estufa de sombrite. O processo de germinação torna-se visível aos dois dias, pela protrusão da raiz primária branca (figura 28). Esta se alonga lentamente (figura 29), até que, aos 19 dias, é formada a alça hipocotilar e inicia-se a liberação dos cotilédones (figura 30), cuja cor verde se torna mais intensa. Com 22 dias, os cotilédones estão liberados e o epicótilo começa a se alongar. Aos 38 dias, a plântula está constituída (figura 31), apresentando o primeiro par de eofilos unifoliolados já diferenciado, sendo opostos cruzados com o nó cotiledonar. Cada eofilo apresenta um par de estípulas foliáceas pequenas, pulvino, pecíolo e pulvínulo diferenciado. Nesta fase, observam-se as primeiras raízes laterais.

Não se formam outros eofilos. Aos 50 dias, ocorre a abscisão dos cotilédones, após murchamento. Com dois meses (figura 32), diferencia-se o primeiro metafilo, alterno e trifoliolado. Este apresenta pulvino, um par de estípulas foliáceas reduzidas, pecíolo e folíolos sésseis, pulvinulados, o maior deles apical. Na base do par de folíolos, ocorre um par de estipelas diminutas.

Até essa fase, o sistema radicular desenvolve-se pouco, não se observando nodulação.

\section{Discussão}

Os dados apresentados sobre a morfologia das plântulas e plantas jovens demonstram inequivocamente a grande variação que existe entre as tribos de Faboideae. Indicam também a necessidade de novos estudos, que abordem um número cada vez mais elevado de espécies, de modo a se estabelecer amplo conhecimento sobre a família, especialmente abordando ambientes específicos.

Gates (1951) referiu que as espécies de Caesalpinioideae e Mimosoideae pareciam ser todas epígeas, enquanto que, em Faboideae, algumas tribos (como Dalbergieae) eram epígeas, outras (como Sophoreae) eram hipógeas e outras ainda (como Phaseoleae) representavam transições, apresentando tanto germinação epígea quanto hipógea.

Vários estudos confirmaram que as espécies de Caesalpinioideae e Mimosoideae são fundamentalmente epígeas, com cotilédones de curta duração, 


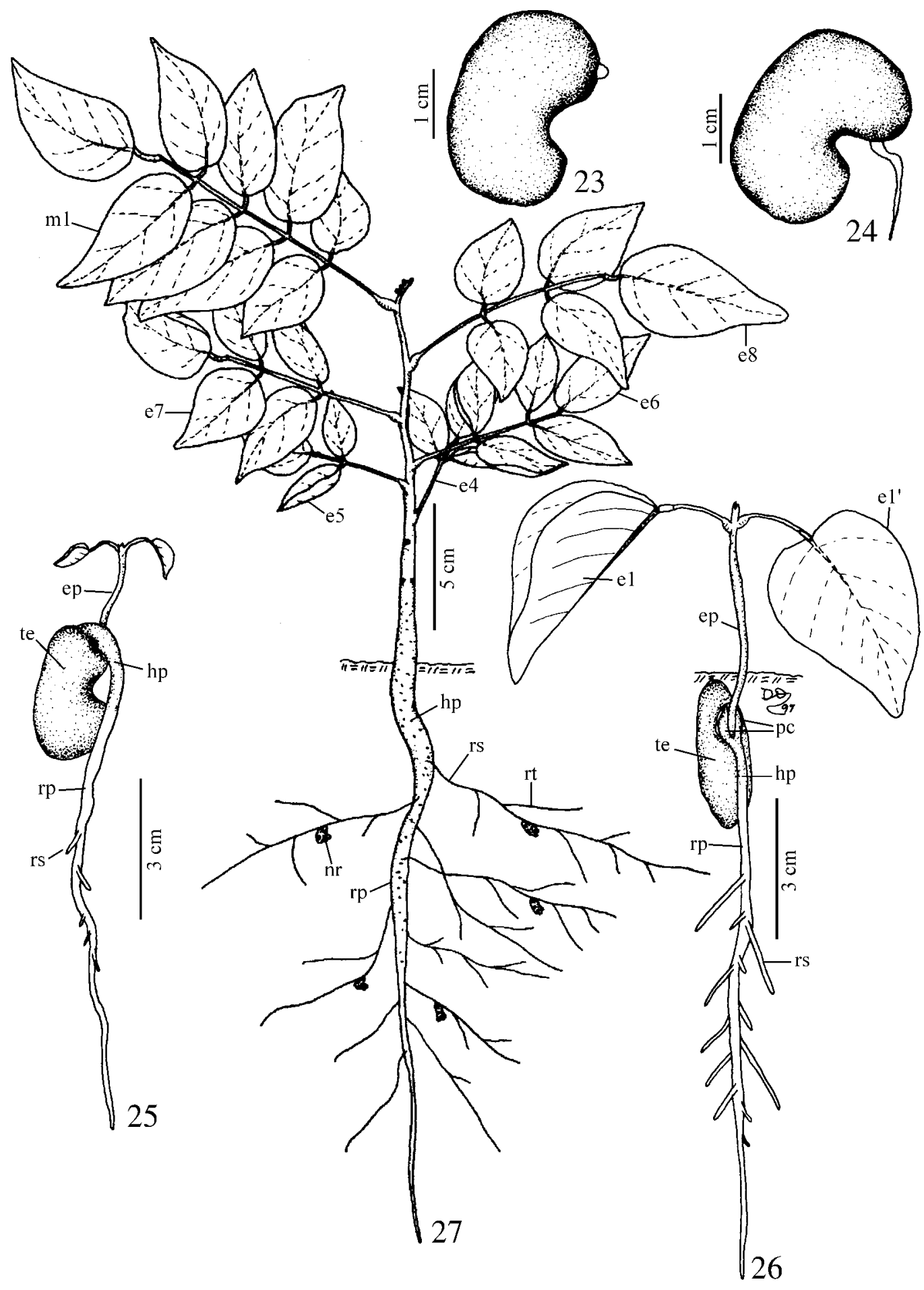

Figuras 23-27. Lonchocarpus muehlbergianus. 23-26. plântula. 23. com 3 dias. 24. com 5 dias. 25. com 12 dias. 26. com 20 dias. 27. planta jovem com 6 meses. (e1- e1': primeiro par de eofilos, e4-e8: série de eofilos, ep: epicótilo, hp: hipocótilo, m1: primeiro metafilo, nr: nódulo radicular, pc: pecíolo cotiledonar, rp: raiz primária, rs: raiz secundária, rt: raiz terciária, te: tegumento). 


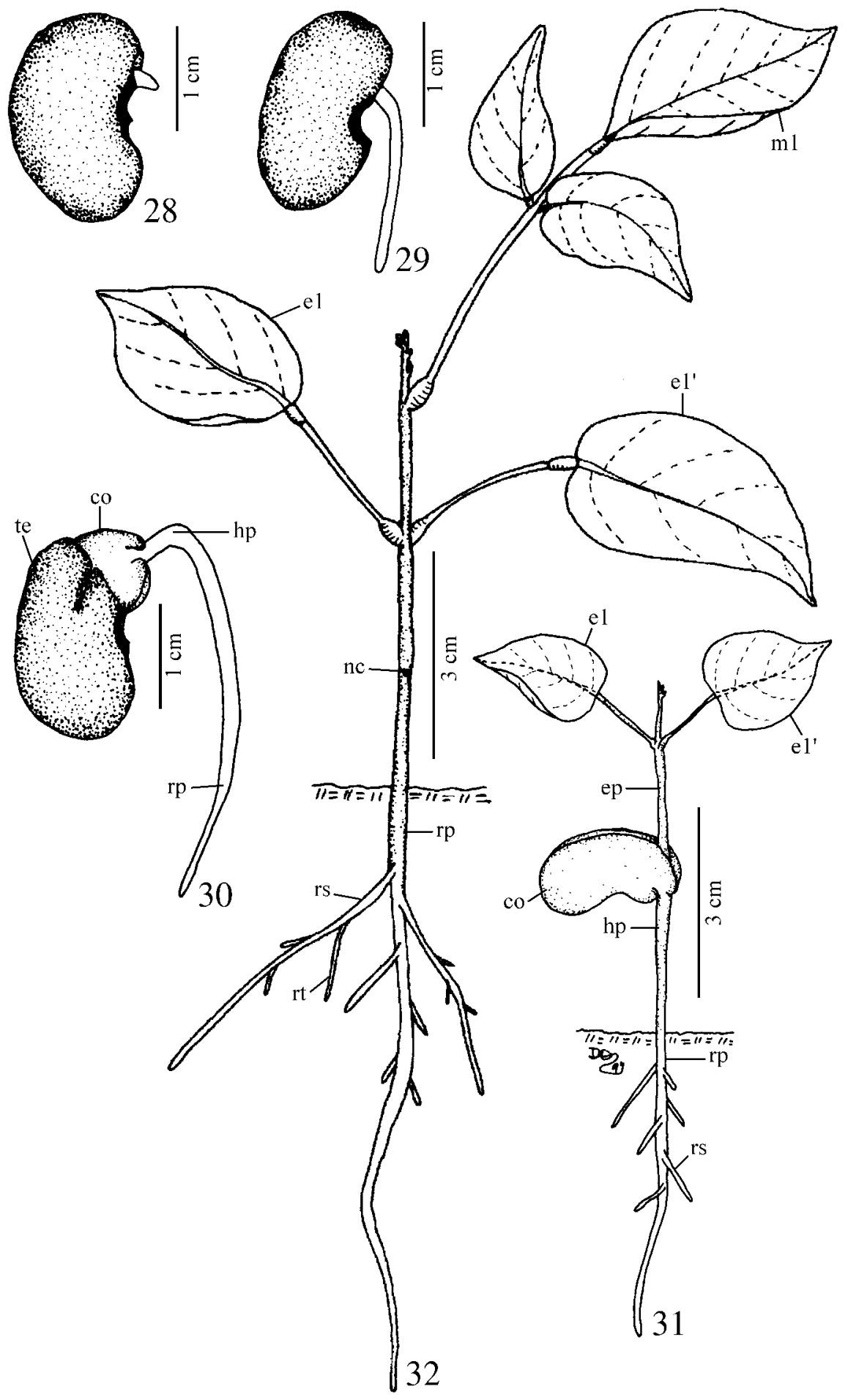

Figuras 28-32. Platycyamus regnellii. 28-31. plântula. 28. com 2 dias. 29. com 8 dias. 30. com 19 dias. 31. com 37 dias. 32. planta jovem com 2 meses. (co: cotilédone, e1-e1': primeiro par de eofilos, ep: epicótilo, hp: hipocótilo, m1: primeiro metafilo, nc: nó cotiledonar, rp: raiz primária, rs: raiz secundária, rt: raiz terciária, te: tegumento). 
foliáceos, que podem também conter alguma reserva ou absorvê-la do endosperma. Nas Faboideae, no entanto, prevalecem espécies hipógeas, que exibem cotilédones carnosos (Polhill et al. 1981).

Duke \& Polhill (1981) consideram as plântulas de Faboideae extremamente variadas, especialmente nas tribos que abrangem espécies lenhosas, como são as englobadas por este trabalho. Em Tephrosieae, é comum o primeiro eofilo ser unifoliolado, tendência que se estende a algumas tribos mais avançadas, como é o caso de Phaseoleae (Polhill et al. 1981). Estas podem ser fanerocotiledonares ou criptocotiledonares, mas sempre com cotilédones carnosos e os primeiros eofilos opostos e unifoliolados (Duke \& Polhill 1981).

Dentre as espécies estudadas destas tribos de Faboideae, observaram-se dois tipos de plântulas: epígeo-carnosas em duas das espécies, e hipógeas, nas outras quatro. As espécies das tribos Sophoreae e Swartzieae se mostraram hipógeas. Em Phaseoleae, Erythrina speciosa apresentou plântula epígeocarnosa. Na tribo Tephrosieae, ocorreram os dois tipos de plântula, um em cada espécie. É interessante destacar a similaridade entre as plântulas e plantas jovens de Platycyamus regnellii (Tephrosieae) e Erythrina speciosa (Phaseoleae) que, excetuando-se características de tamanho, diferem somente pela presença de espinhos e nectários extra-florais em $E$. speciosa.

A despeito de existir uma tendência dos tipos de plântula se tornarem fixos nas tribos mais avançadas, ocasionalmente ocorrem reversões como em Phaseoleae, em que as plântulas passam de hipógeas a epígeas em algumas espécies (Polhill et al. 1981). Este fato explica a estreita correlação mencionada entre Erythrina speciosa e Platycyamus regnellii, a primeira integrante de Phaseoleae, tribo derivada diretamente de Tephrosieae, onde Platycyamus regnellii está enquadrada.

Dentro do gênero Erythrina é reconhecida grande variação estrutural nas plântulas. Burkart (1952) verificou que E. crista-galli, E. falcata e E. Dominguezii, espécies argentinas do gênero, apresentavam germinação hipógea. Já Flores \& Rivera (1984) estudaram seis espécies de Erythrina ( $E$. berteroana, E. costaricensis, E. crista-galli, E. fusca, E. lanceolata e E. poeppigiana) ocorrentes na Costa Rica, verificando que todas são epígeas e fanerocotiledonares. Deve-se ressaltar que E. cristagalli foi incluída nos dois trabalhos referidos, figurando como hipógea no primeiro e epígea no segundo. É possível que haja algum problema de identificação da espécie em algum dos dois trabalhos, de modo que este dado deve ser considerado com o devido cuidado. Em E. speciosa, neste trabalho, observou-se germinação caracteristicamente epígea e fanerocotiledonar.

Uma característica das Fabaceae que merece destaque é a capacidade de nodulação radicular por bactérias do gênero Rhizobium, fixadoras de nitrogênio. Grande parte das espécies arbóreas nativas ainda carece de informação a respeito da capacidade de nodulação (Silva et al. 1988). Segundo Corby (1981), a nodulação é geral para as espécies de Mimosoideae e Faboideae, sendo incomum em Caesalpinioideae. Analisando as espécies estudadas neste trabalho, verifica-se que a nodulação por estirpes nativas de Rhizobium, ou seja, sem que se fizesse nenhuma inoculação, só não ocorreu em Holocalyx balansae e em Platycyamus regnellii. Vários podem ser os motivos da ausência de nódulos nesses sistemas radiculares, além da incapacidade de nodulação. É possível que tenha havido problemas de especificidade das estirpes do solo com essas espécies, porém o mais provável é que a nodulação seja tardia e, como as espécies só foram acompanhadas até a formação do primeiro metafilo (durante quatro e dois meses, respectivamente), os nódulos não estavam formados e não puderam ser relatados.

Agradecimentos - À Dra. Celia Massa Beltrati, pela orientação e ao Dr. José Flávio Cândido Júnior, pela leitura crítica do manuscrito. Ao CNPq e CAPES/PICD, pelas bolsas de doutorado concedidas. À FUNDUNESP, pelo auxílio referente ao Processo nํㅡㄴ 242/92-DFP/F/CAV.

\section{Referências bibliográficas}

AMO, S. 1979. Clave para plántulas y estados juveniles de especies primarias de una Selva Alta Perennifolia em Veracruz, México. Biotica 4:59-108.

BURKART, A. 1952. Las leguminosas argentinas silvestres y cultivadas. 2 ed. Acme Agency, Buenos Aires.

COMPTON, R.H. 1912. Investigation of the seedling structure in the Leguminosae. Journal of the Linnean Society of London Botany 41:1-122.

CORBY, H.D.L. 1981. The systematic value of leguminous root nodules. In Advances in legume systematics (R.M. Polhill \& P.H. Raven, eds.). Royal Botanic Gardens, Kew, p.657-669. 
DUKE, J.A. 1965. Keys for the identification of seedlings of some prominent woody species in eight forest types in Puerto Rico. Annals of the Missouri Botanical Garden 52:314-350.

DUKE, J.A. 1969. On tropical seedlings. I. Seeds, seedlings, systems and systematics. Annals of the Missouri Botanical Garden 56:125-161.

DUKE, J.A. \& POLHILL, R.M. 1981. Seedlings of Leguminosae. In Advances in legume systematics (R.M. Polhill \& P.H. Raven, eds.). Royal Botanic Gardens, Kew, p.941-949.

FLORES, E.M. \& RIVERA, D.I. 1984. Clave para semillas y plántulas de las especies del género Erythrina en el Valle Central, Costa Rica. Revista de Biologia Tropical 32:241-252.

GARWOOD, N.C. 1983. Seed germination in a seasonal tropical forest in Panama: a community study. Ecological Monographs 53:159-181.

GARWOOD, N.C. 1995. Studies in Annonaceae. XX. Morphology and ecology of seedlings, fruits and seeds of selected Panamanian species. Botanische Jahrbücher für Systematik 117:1-152.

GARWOOD, N.C. \& HUMPHRIES, C.J. 1993. Seedling diversity in the neotropics. NERC News 27:20-23.

GATES, R.R. 1951. Epigeal germination in the Leguminosae. Botanical Gazette 113:151-157.

LORENZI, H. 1992. Árvores brasileiras: manual de identificação e cultivo de plantas arbóreas nativas do Brasil. Editora Plantarum, Nova Odessa.

MIQUEL, S. 1987. Morphologie fonctionelle de plantules d'especes forestières du Gabon. Bulletin du Museum National d'Histoire Naturelle, Section B, Adansonia, Botanique Phytochimie 9:101-121.
NG, F.S.P. 1973. Germination of fresh seeds of Malaysian trees. Malaysian Forester 36:54-65.

NG, F.S.P. 1978. Strategies of establishment in Malayan forest trees. In Tropical trees as living systems (P.B. Tomlinson \& M.H. Zimmermann, eds.). University Press, Cambridge, p.129-162.

OLIVEIRA, D.M.T. 1997. Análise morfológica comparativa de frutos, sementes, plântulas e plantas jovens de 30 espécies arbóreas de Fabaceae ocorrentes no Estado de São Paulo. Tese de doutorado, Universidade Estadual Paulista, Rio Claro.

PARRA, P. 1984. Estudio de la morfologia externa de plântulas de Calliandra gracilis, Mimosa albida, Mimosa arenosa, Mimosa camporum y Mimosa tenuiflora. Revista de la Facultad de Agronomia (Maracay) 13:311-350.

POLHILL, R.M. 1981. Papilionoideae. In Advances in legume systematics (R.M. Polhill \& P.H. Raven, eds.). Royal Botanic Gardens, Kew, p.192-208.

POLHILL, R.M., RAVEN, P.H. \& STIRTON, C.H. 1981. Evolution and systematics of the Leguminosae. In Advances in legume systematics (R.M. Polhill \& P.H. Raven, eds.). Royal Botanic Gardens, Kew, p.1-26.

RICARDI, M., TORRES, F., HERNÁNDEZ, C. \& QUINTERO, R. 1977. Morfologia de plantulas de arboles venezolanos. I. Revista Florestal Venezolana 27:15-56.

SILVA, M.F., GOLDMAN, G.H., MAGALHÃES, F.M. \& MOREIRA, F.W. 1988. Germinação natural de 10 espécies arbóreas da Amazônia - I. Acta Amazonica 18:9-26.

TORRES, E.B. 1985. Identificacion de plantulas de algunas especies arboreas del bosque de Niebla. Perez-Arbelaezia 1:39-95. 